${ }^{4}$ Khatri, I. M., and Freis, E. D., Circulation, 1969, 39, 785.

5 Bristow, J. D., et al., Cardiovascular Research, 1969, 3, 476.

${ }^{6}$ Bevan, A. T., Honour, A. J., and Stott, F. H., Clinical Science, 1968, 36, 329.

${ }^{7}$ Littler, W. A., et al., British Medical fournal, 1972, 3, 76.

${ }^{8}$ Agnew, H. V., Webb, W. B., and Williams, R. L., Psychophysiology, 1966, $2,263$.
${ }^{9}$ Smyth, H. S., Sleight, P., and Pickering, G. W., Circulation Research, 1969, 24, 109.

10 Guazzi, M., Baccelli, G., and Zanchetti, A., American fournal of Physiology, $1968,214,969$

11 Littler, W. A., and Honour, A. J., Quarterly fournal of Medicine, 1974, 43, 441.

12 Guazzi, M., Ellsworth, O. T., and Freis, E. D., Cardiovascular Research, $1971,5,71$.

\title{
Detection of Cannabis Products in Urine by Radioimmunoassay
}

\author{
VINCENT MARKS， DERRICK TEALE， DENYS FRY
}

British Medical fournal, 1975, 3, 348-349

\begin{abstract}
Summary
A radioimmunoassay specific for the closed, three-ringed cannabinoid nucleus was used to detect and measure cannabis products in urine. Of the 475 urine specimens examined 82 came from hospital inpatients not suspected of taking drugs. None of these contained tetrahydrocannabinol cross-reacting cannabinoids (THC-CRC). The other 393 specimens were from patients known or suspected to be taking various drugs. Of these, 51 out of 162 from one hospital treatment clinic and 19 out of 50 from another were positive for THC-CRC. Out of 107 urine specimens from an independent drug treatment clinic 71 were positive for THC-CRC, as were 13 out of 74 specimens from patients in whom drug misuse was suspected or thought possible.
\end{abstract}

\section{Introduction}

Analysis of urine for drugs of abuse is commonplace in many clinical laboratories, ${ }^{1}$ the main emphasis in the U.K., as elsewhere, being on narcotics, amphetamines, and barbiturates. ${ }^{2-4}$ From time to time, however, other drugs, such as methaqualone, ${ }^{5}$ assume importance. Thin-layer chromatography constitutes the methodological basis of most drug-detection systems, but latterly immunoassay techniques have become important. ${ }^{\circ}$

Until recently no method of urine analysis was available for detecting cannabis use. Thus there is a dearth of reliable data on which to base present and future legislative policy regarding this drug. The introduction of an exquisitely sensitive, highly specific radioimmunoassay technique ${ }^{7-9}$ for measuring cannabis derivatives in blood and urine has enabled us for the first time to investigate cannabis use objectively.

\footnotetext{
Department of Biochemistry (Division of Clinical Biochemistry), University of Surrey, Guildford GU2 5 XH

VINCENT MARKS, D.M., F.R.C.PATH., Professor of Clinical Biochemistry DERRICK TEALE, PH.D., Research Fellow
}

Epsom Hospital Laboratories, West Park Hospital, Epsom DENYS FRY, B.SC., Biochemist

\section{Materials and Methods}

Urinary tetrahydrocannabinol cross-reacting cannabinoids (THCCRC) were measured by a radioimmunoassay technique specific for the closed, three-ringed cannabinoid nucleus. ${ }^{9}$ Specimens for analysis were selected by one of us. All urine samples received for analysis for drugs at the area laboratory at West Park Hospital between December 1974 and February 1975 were analysed for THC-CRC at regular intervals in number-coded batches at the University of Surrey. Included in random order were specimens of control urine. All the specimens came from patients living in the Greater London or Surrey areas and were collected between December 1974 and February 1975.

A total of 475 specimens were analysed. Of these, 82 were from hospital inpatients in whom drug abuse was not (and never had been) queried but in whom a quantitative measurement of urinary steroids, catecholamines, or some other endogenous product had been requested for diagnostic purposes; 319 came from two hospital treatment clinics (A and B) and one independent drug treatment clinic (C), for all of which the West Park Hospital laboratory provides a routine service for the analysis of drugs in urine $;^{10}$ and 74 came from other sources, including general medical outpatient departments, psychiatric clinics, and general practitioners' surgeries, with a request for routine analysis for drugs. This last, miscellaneous group included 17 specimens from eight residents of a hostel for former drug addicts. A condition for entry to and continued residence at the hostel is complete abstinence from habit-forming drugs, and to ensure compliance with this rule urine samples are tested regularly for narcotics, amphetamines, and barbiturates.

For this investigation urine samples containing less than $10 \mu \mathrm{g}$ of THC-CRC per 1 of urine were regarded as negative. More than a third of the samples from the drug treatment clinics came from patients who provided two or more specimens.

\section{Results}

All 82 urine specimens from the hospital inpatients were negative for cannabis (see fig.). Of the 162 specimens from clinic A and the 50 from clinic B $51(31 \%)$ and $19(38 \%)$, respectively, were positive for THC-CRC; $71(66 \%)$ of the 107 specimens from clinic C contained THC-CRC, as did $13(18 \%)$ of the 74 "miscellaneous" specimens. Investigation into the origin of the THC-CRC-positive specimens in the miscellaneous group disclosed that six of them came from the rehabilitation hostel and were provided by three people.

Altogether 32 patients provided urine specimens on three or more days. The results of quantitative analysis of the 113 specimens so provided are shown in the table.

\section{Discussion}

The radioimmunoassay used here is specific for the three-ringed cannabinoid nucleus. ${ }^{9}$ It does not distinguish between $\Delta^{9}$-THC, the most pharmacologically active natural cannabinoid, and its 


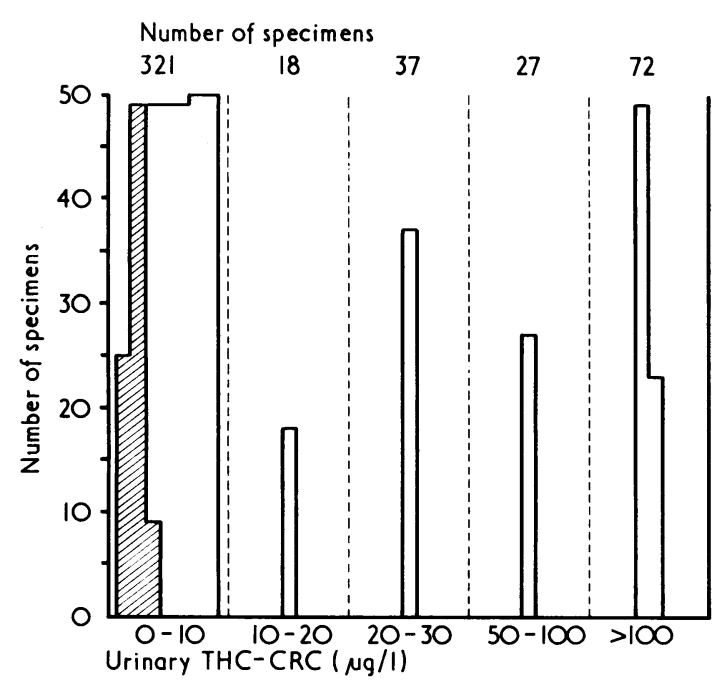

Urinary THC-CRC in 475 specimens analysed by radioimmunoassay. Hatched area represents control specimens.

THC-CRC Content of Urine $(\mu \mathrm{g} / \mathrm{l})$ in 32 Patients from Drug Dependence Clinics in whom Three or More Specimens were Received for Analysis

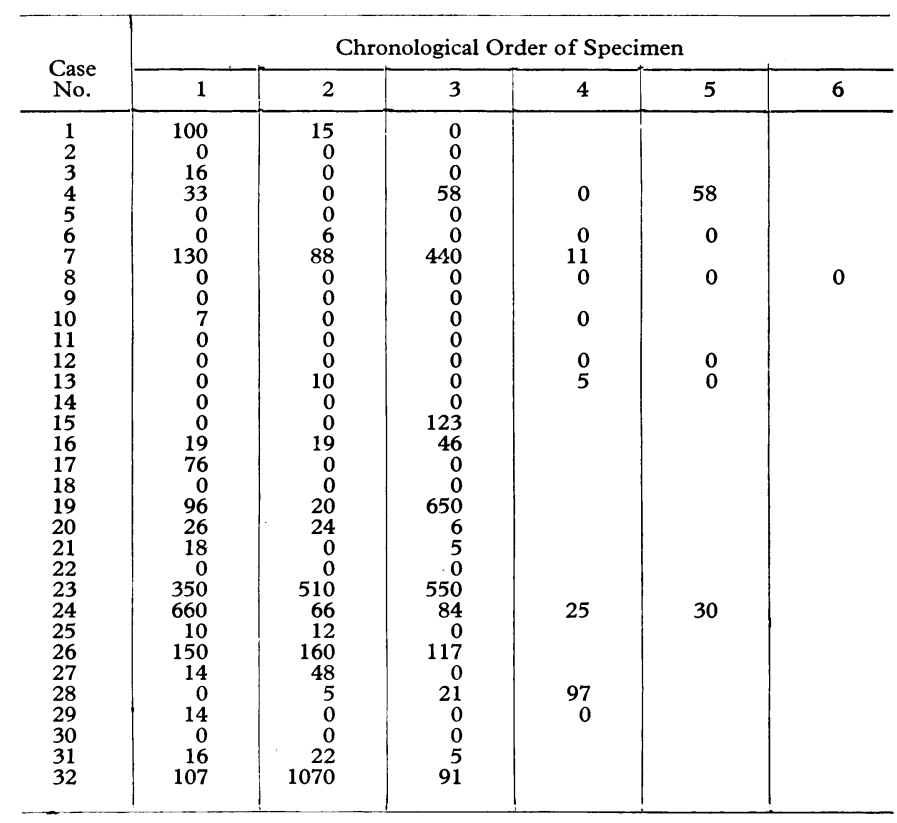

major metabolite 11-hydroxy-THC, which is equally psychoactive. ${ }^{11}$ This is of inestimable advantage in the detection of cannabis use by urine analysis because $\Delta^{9}$-THC is not itself excreted in the urine in more than infinitesimal amounts. ${ }^{12}$ The absence of false-positive results in the 82 hospital inpatients receiving treatment with a wide range of drugs confirms our earlier conclusions on the assay ${ }^{9}$ and its suitability for clinical and epidemiological purposes.

Hitherto, attempts to detect and measure cannabis derivatives in blood and urine have been either unsuccessful or so tedious, expensive, and technically demanding ${ }^{13}{ }^{14}$ as to be quite impracticable except for small-scale research investigations. A radioimmunoassay for THC-CRC of different sensitivity and specificity to our own has been described in preliminary form by Gross et al. ${ }^{15}$
Estimates of the frequency of cannabis use among known narcotics users in the U.K. made by several groups ${ }^{1-19}$ on the basis of personal histories, which are notoriously unreliable in such patients, without objective assessment have ranged from $86 \%$ to $100 \%$. These estimates are much higher than were actually observed and may represent the difference between sporadic and more or less constant use. The rate of cannabis use in our study was similar in patients attending the two hospital treatment clinics but was substantially higher in patients attending the independent clinic, at which treatment with narcotics, especially heroin and methadone, is specifically avoided.

The rate of cannabis use as shown by urine analysis in patients suspected of but not necessarily admitting to misusing drugs was $10 \%$. The relatively high rate- 3 out of 8 patients, and 6 out of 17 urine specimens - of cannabis use by "rehabilitated" narcotics users living in a hostel was unsuspected. The concentration of a drug in the urine is at best a poor guide to the amount actually taken, since a low concentration can be the result of either a large dose taken a long time previously or a small dose taken a short time previously. Nevertheless, the wide range of values for urinary THC-CRC concentrations observed (nil to over 1500 $\mu \mathrm{g} / \mathrm{l})$ lends credence to the suggestion by Fairbairn et $a{ }^{2}{ }^{20}$ that the daily cannabis intake may vary by more than a hundredfold among persons admitting to using the drug.

The quantitative urine analysis data appeared (fig.) to reveal two populations among the patients attending the drug dependence clinics-those who use a lot of cannabis and thus excrete large amounts of THC-CRC in their urine, and those who abstain from cannabis completely. This concept gained support when the data on the 32 individual patients from whom multiple samples were obtained and examined. There was an unmistakable tendency (admittedly not absolute) for the specimens from one patient to be either all negative or all positive, though the actual concentration of THC-CRC might vary considerably. Clearly more extensive investigation is necessary before firm conclusions concerning the prevalence of cannabis use among drug-dependent persons and others can be drawn. Nevertheless, it seems reasonable to suppose that radioimmunoassay could provide the objective basis for such study.

This work was made possible through the generosity of the M.R.C.

\section{References}

1 Marks, V., British fournal of Addiction, 1966, 61, 291.

2 Dole, V. P., Kim, W. K., and Eglitis, I., Fournal of the American Medical Association, 1966, 198, 349.

${ }^{3}$ Davidow, B., Petri, N. L., and Quame, B., American fournal of Clinical Pathology, 1968, 50, 714 .

${ }^{4}$ Marks, V., and Fry, D., Proceedings of the Association of Clinical Biochemists, 1968, 5, 95.

${ }^{5}$ Allen, J. T., Fry, D., and Marks, V., Lancet, 1970, 1, 951.

${ }^{6}$ Mule, S. J., et al., Radioimmunoassay for Drugs Subject to Abuse. Cleveland, CRC Press, 1974

7 Teale, J. D., et al., Nature, 1974, 249, 154.

8 Teale, J. D., et al., Lancet, 1974, 2, 553.

9 Teale, J. D., et al., Fournal of Pharmacy and Pharmacology, 1975, 27, 465.

10 Marks, V., et al., British Medical fournal, 1969, 2, 153.

11 Hollister, L. E., in Research Advances in Alcohol and Drug Problems, ed. R. J. Gibbins, et al., Vol. 1, p. 243. New York, Wiley, 1974.

12 Hollister, L. E., et al., Research Communications in Chemical Pathology and Pharmacology, 1974, 8, 579.

13 Agurell, S., et al., Fournal of Pharmacy and Pharmacology, 1973, 25, 554

14 Rosenfeld, J. J., et al., Analytical Chemistry, 1974, 46, 2232.

15 Gross, S. J., et al., Nature, 1974, 252, 581.

16 Kosviner, A., et al., Lancet, 1968, 1, 1189.

17 Anumoyne, A., and McClure, J. L., British Fournal of Addiction, 1970, $65,25$.

${ }_{18}$ Mitcheson, M., et al., Lancet, 1970, 1, 606.

19 Stimson, G. V., and Ogborne, A. C., Lancet, 1970, 1, 1163.

${ }^{20}$ Fairbairn, J. W., et al., Nature, 1974, 249, 276. 